\title{
Long term results of endoscopic dilatation for corrosive oesophageal strictures
}

\author{
S L Broor, G S Raju, P P Bose, D Lahoti, G N Ramesh, A Kumar, G K Sood
}

\begin{abstract}
Although dilatation is the treatment of choice for most patients with benign oesophageal strictures, there is little information on its efficacy and safety in corrosive oesophageal strictures. Of 123 adults with benign oesophageal strictures treated by endoscopic dilatation, $52(42 \cdot 3 \%)$ had strictures after corrosive ingestion and $39(31.7 \%)$ had peptic strictures. Treatment was considered adequate if the oesophageal lumen could be dilated to $15 \mathrm{~mm}$ and there was complete relief of dysphagia. If dysphagia recurred after adequate initial dilatation, the stricture was dilated again up to $15 \mathrm{~mm}$. Initial dilatation was adequate in $93.6 \%$ of patients with corrosive strictures and this success rate was comparable with that of the peptic stricture group $(100 \%, p>0.05)$. Long term success after adequate initial dilatation was studied in $\mathbf{3 6}$ patients with corrosive strictures (mean follow up $32 \cdot 36(17 \cdot 12)$ months, range $6-60$ ) and 33 patients with peptic strictures (mean follow up $36.32(17.9)$ months, range 6-60). The mean (SEM) number of symptomatic recurrences per patient month during the total follow up period in the corrosive group was significantly higher than that in the peptic group $(0.27(0.04) v 0.07(0.02)$, $\mathrm{p}<0.001)$. The recurrence rate in the corrosive group, however, decreased over time, and after 12 months it was significantly $(p<0.001)$ lower than the recurrence rate in the first six months. After $\mathbf{3 6}$ months, the difference in the recurrence rate in the two groups was not significant $(p>0.05)$. Only nine oesophageal perforations occurred during a total of 1373 dilatation treatments (procedure related incidence $0.66 \%$ ), and eight of these were in the corrosive stricture group. These patients were managed conservatively and subsequently strictures were dilated adequately in all. Endoscopic dilatation is safe and effective for short and long term relief of dysphagia in patients with corrosive oesophageal strictures.
\end{abstract}

(Gut 1993; 34: 1498-1501)

Department of

Gastroenterology,

GB Pant Hospital,

New Delhi, India

$S$ L Broor

G S Raju

P P Bose

D Lahoti

G N Ramesh

A Kumar

G K Sood

Correspondence to: Professor S L Broor Department of

Gastroenterology, GB Pant

Hospital, New Delhi-110002, India.

Accepted for publication 8 April 1993 patients..$^{2-7}$ The reported experience is mostly in patients with peptic strictures ${ }^{1-8}$ and there is little information on the efficacy and safety of this treatment in patients with corrosive oesophageal strictures.

Corrosive ingestion, especially of acids, is a very common cause of oesophageal injury and strictures in India ${ }^{9-11}$; and was reported to be the commonest aetiology in one study. ${ }^{11}$ In several large series from other countries, however, corrosive ingestion was responsible for only $1-4 \%$ of benign oesophageal strictures. ${ }^{1578}$ Corrosive strictures are frequently very tight, long, eccentric and multiple." There is an undocumented belief that these patients have a very high stricture recurrence rate because of extensive oesophageal damage and fibrosis. For these reasons, patients with corrosive strictures often undergo surgery, which carries significant morbidity and mortality. ${ }^{12}$ We have reported that endoscopic dilatation is an effective and safe short term treatment for corrosive oesophageal strictures. ${ }^{11}$ The natural history of these patients after adequate initial dilatation is not known, and there is no information on the long term success of dilatation. In this study, we report the long term results of dilatation in these patients. Besides efficacy, we also wanted to determine the safety of this treatment.

\section{Methods}

\section{PATIENTS}

One hundred and twenty three adults were treated for benign oesophageal strictures over the six years, 1986-92. All patients presented with dysphagia of varying grades. The site, length of stricture(s), and the degree of narrowing of oesophageal lumen were assessed by radiologic and endoscopic examinations. Where a malignant cause for the stricture was suspected, this was excluded by endoscopic biopsies and cytological examination.

\section{DILATATION}

The dilatation was done in most patients as an outpatient procedure. Savary-Gilliard bougies or Eder-Puestow metal olives of increasing size were passed over a guide wire which had been positioned with the help of a fibreoptic endoscope. Based on our clinical experience, we arbitrarily chose to dilate these patients at weekly intervals and one to six bougies were usually passed on each occasion, depending upon the patient's tolerance and the tightness of strictures. In high risk patients, dilatation was initially done under fluoroscopic control, subsequently in most patients the procedure was done without the fluoroscopy.

Dilatation was considered adequate when the oesophageal lumen could be dilated up to 15 $\mathrm{mm}$. Any subsequent dilatations depended upon the recurrence of dysphagia. Patients who had strictures caused by reflux oesophagitis were advised to use $\mathrm{H}_{2}$ receptor antagonists or the 
proton pump inhibitor, omeprazole, together with other antireflux measures such as raising the head of the bed, early dinner, and weight reduction.

Where a complication such as perforation was suspected, urgent chest $\mathrm{x}$ ray and oesophagogram using a water soluble contrast medium were done. The patient was fasted until the possibility of perforation was ruled out. If the diagnosis of perforation was confirmed, the patient was given intravenous fluids and antibiotics and was advised to take nothing by mouth. An immediate surgical consultation was sought and the patient was managed jointly with the surgical team.

\section{RESPONSE}

The outcome of treatment was judged on the basis of improvement in dysphagia, which was graded as follows ${ }^{13}$ :

Grade 0 - taking a normal diet;

Grade 1 - unable to swallow certain solids;

Grade 2-can swallow only semisolid soft diet;

Grade 3 - can swallow liquids only;

Grade 4-unable to swallow even liquids in adequate amounts.

The response to dilatation was considered 'good' if the stricture could be dilated up to $15 \mathrm{~mm}$ with complete relief of symptoms (dysphagia grade 0 ). When the stricture could not be adequately dilated and there was minimal or no improvement in symptoms, the response was considered 'poor'.

\section{FOLLOW UP}

After adequate initial dilatation $(15 \mathrm{~mm})$, patients were instructed to attend for follow up at six to eight week intervals, or earlier in case of a recurrence of dysphagia. Since it is not practical to assess the recurrence of strictures by repeated radiologic and endoscopic examinations, repeat dilatation up to $15 \mathrm{~mm}$ was done whenever dysphagia recurred (symptomatic recurrence). During recurrence, dilatation was done without any radiological evaluation of the oesophagus. If dysphagia persisted despite dilatation, barium swallow examination was undertaken to assess the oesophageal lumen.

\section{STATISTICS}

Results are expressed as mean (SEM). Differences between the groups were determined by Wilcoxon rank sum test (unpaired). Differences were considered significant only when the $\mathrm{p}$ value was $<0 \cdot 05$.

\section{Results}

We studied 123 adult patients (76 men and 47 women; mean (SD) age $38.7(18.7)$ years), age range 18-84 years) with benign oesophageal strictures treated by dilatation over the six years 1986-92. The aetiology of the oesophageal strictures is shown in Table I. Corrosive injury was the commonest cause, followed by peptic and sclerotherapy induced strictures. With regard to the 52 patients in the corrosive group
TABLE I Aetiology of benign oesophageal strictures

\begin{tabular}{lc}
\hline Aetiology & No of patients \\
\hline Corrosive ingestion: & 52 \\
$\quad$ Acids (32) & \\
Alkali (14) & \\
$\quad$ Undefined (6) & 39 \\
Peptic & 21 \\
Sclerotherapy & 1 \\
Postoperative & 4 \\
Radiation & 1 \\
Scleroderma & 1 \\
Web & 4 \\
Idiopathic & 123 \\
Total & \\
\hline
\end{tabular}

(30 men, 22 women; age range 18-55 years, mean (SD) age $26 \cdot 4(9 \cdot 6)$, the strictures were due to acid ingestion in 32 patients and alkali ingestion in 14 patients. Eighteen patients had multiple strictures and 24 had long $(5-15 \mathrm{~cm})$ and eccentric strictures.

ADEQUATE INITIAL DILATATION

Five of 52 patients with corrosive strictures were lost to follow up before adequate initial dilatation could be done and have therefore been excluded from the analysis. Forty four $(93.6 \%)$ of the remaining 47 patients were dilated successfully and had complete relief of dysphagia. The success rate in the corrosive group was comparable $(p>0.05)$ with that in the peptic stricture group (100\%). Those patients who did not respond to dilatation treatment were advised to have surgery. Although the success rate in the two groups was similar, the number of treatments required to achieve adequate dilatation was significantly $(\mathrm{p}<0.05)$ higher in the corrosive (median 8, range 1-35) than the peptic stricture group (median 1, range 1-33).

\section{LONG TERM FOLLOW UP}

Only those patients who completed at least six months of follow up after adequate initial dilatation are included in the analysis of the long term results. Of 69 patients with more than six months follow up, 36 belonged to the corrosive group and 33 had a peptic stricture. The mean (SD) periods of follow up in the corrosive and peptic stricture groups were $32 \cdot 36(17 \cdot 12)$ months (range 6-60 months) and 36.32 (17.9) (range 6-60 months) respectively.

The dysphagia recurrence rate during follow up was higher in the corrosive than in the peptic stricture group. The mean (SEM) numbers of symptomatic recurrences per patient month in the corrosive and peptic stricture groups were $0.27(0.04)$ (range $0-1 \cdot 2)$ and 0.07 $(0.02)$ (range $0-0.52$ ) respectively (Fig 1 ). The difference between the two groups was statistically significant $(p<0.001)$. The numbers of patients who had at least one recurrence $(94.44$ $v 54.55 \%, \mathrm{p}<0.02)$, five recurrences $(55.56 v$ $18.18 \%, \mathrm{p}<0.02$ ), and 10 recurrences (33 v $9 \cdot 1 \%, \mathrm{p}<0.01)$ were significantly higher in the corrosive stricture group than in the peptic stricture group.

Although the total number of recurrences during the entire follow up period was higher in the corrosive group, there was a noticeable 
Figure1: Number of symptomatic recurrences in the corrosive $(n=36)$ and peptic strictures $(n=33)$ patients on follow up (range 6-60 months) after adequate initial dilatation. The recurrence rate was significantly $(p<0.001)$ higher in the corrosive group than in the peptic stricture group.

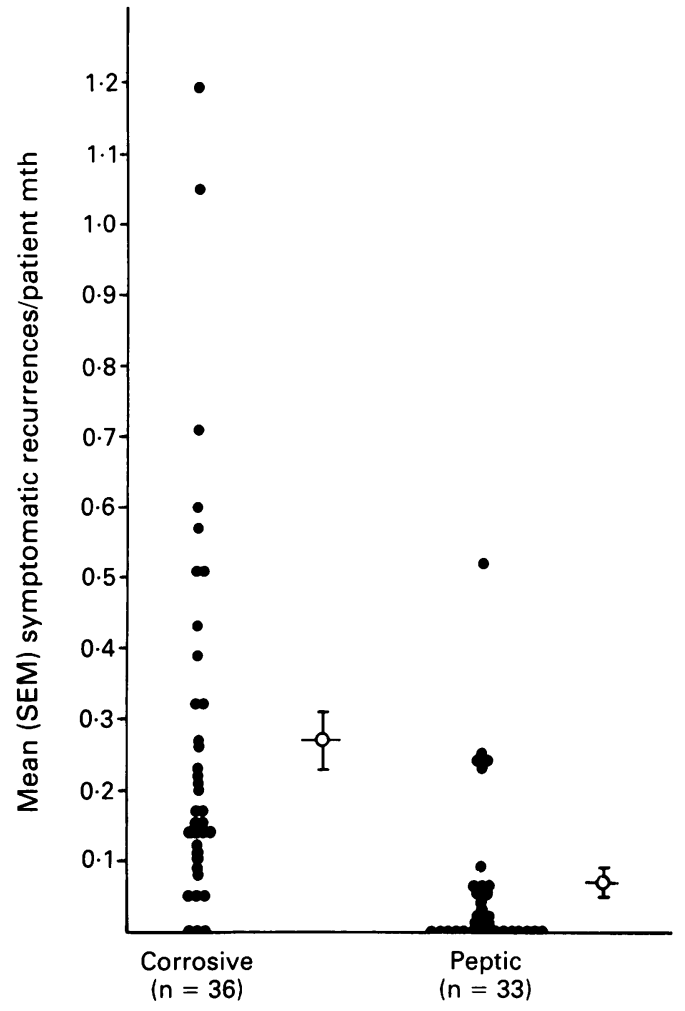

decrease in the recurrence rate in this group over time (Fig 2). After 12 months, the recurrence rate was significantly $(\mathrm{p}<0.001)$ lower than that observed during the first six months. After 36 months, the recurrence rate in the corrosive group was comparable with that in the peptic stricture group $(\mathrm{p}>0.05)$.

Table II shows the pattern of recurrence over the entire period of follow up in patients with corrosive strictures. During the first six months,

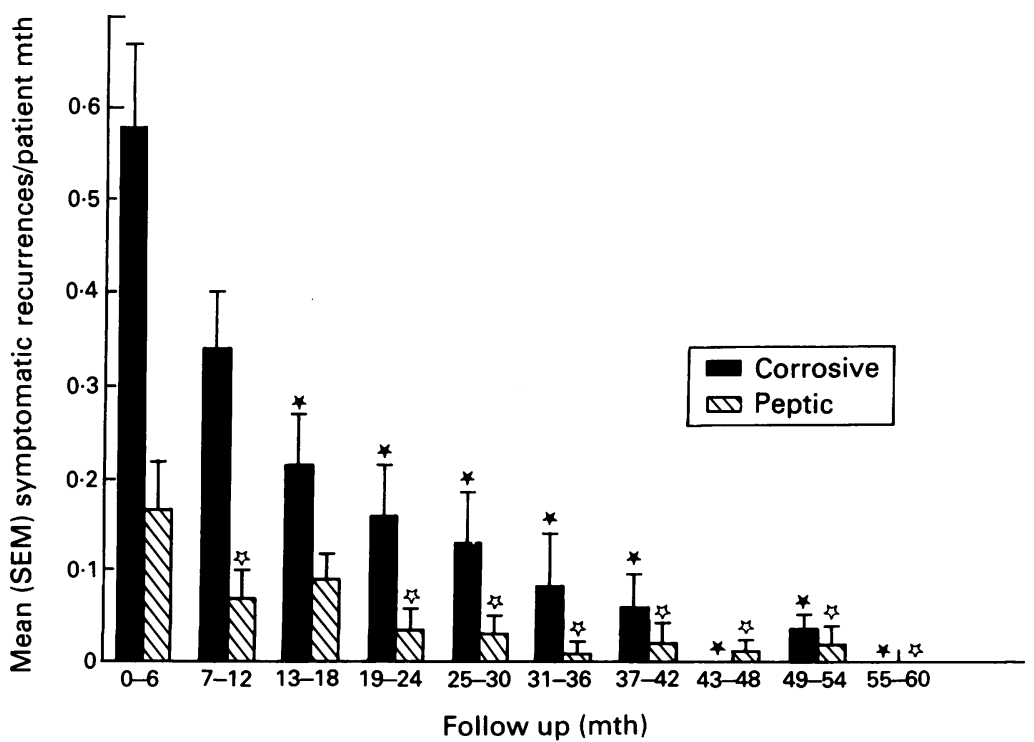

Figure 2: Mean number of symptomatic recurrences per patient month (mean (SEM)) in corrosive and peptic stricture groups. Symptomatic recurrences during the first 6 month interval are compared with those during subsequent 6 month intervals. In the corrosive group the recurrence rate shows a decrease with increasing follow up. After 12 months it was significantly lower $\left({ }^{\star} p<0.001\right)$ than the recurrence rate during the first 6 months. When compared with the peptic stricture group, the recurrence rate was significantly $(p<0.05)$ higher only up to 36 months, thereafter the difference in the two groups was not significant. The recurrence rate decreased in the peptic stricture group also on follow up («p<0.01 compared with the recurrence rate in the first 6 months).
TABLE II Dilatation for recurrence in patients with corrosive strictures after adequate initial dilatation

\begin{tabular}{llccr}
\hline $\begin{array}{l}\text { Follow up } \\
\text { duration } \\
\text { (mth) }\end{array}$ & $\begin{array}{l}\text { No of } \\
\text { patients }\end{array}$ & \multicolumn{3}{c}{$\begin{array}{l}\text { No of patients requiring } 0,1, \text { or } \geqslant 2 \\
\text { dilatations over } 6 \text { mth }\end{array}$} \\
\cline { 2 - 5 } & 0 & 1 & $\geqslant 2$ \\
\hline $0-6$ & 36 & 4 & 8 & 24 \\
$7-12$ & 36 & 14 & 7 & 15 \\
$13-18$ & 31 & 16 & 6 & 9 \\
$19-24$ & 26 & 17 & 3 & 6 \\
$25-30$ & 19 & 12 & 5 & 2 \\
$31-36$ & 18 & 15 & 1 & 2 \\
$37-42$ & 16 & 12 & 3 & 1 \\
$43-48$ & 12 & 11 & 1 & 0 \\
$49-54$ & 9 & 7 & 2 & 0 \\
$55-60$ & 4 & 4 & 0 & 0 \\
\hline
\end{tabular}

only a very small number of patients $(11 \cdot 11 \%)$ did not require dilatation for recurrence. In fact, most $(66 \cdot 7 \%)$ underwent two or more dilatations during this period. With increased duration of follow up, the number of patients who either did not require any dilatation or needed only one dilatation in six months, increased progressively and there was a simultaneous reduction in the number of patients requiring two or more dilatations.

\section{COMPLICATIONS}

Only nine perforations occurred during a total of 1373 dilatation sessions (procedure related incidence of perforation $0.66 \%$ ) in the whole group; eight of these were in the corrosive group (total number of dilatation sessions 990 , procedure related incidence of perforation $0.8 \%$ ). All perforations in the corrosive group occurred in patients with long, tight, and eccentric strictures in whom, after the first few sessions, dilatation was performed without fluoroscopic guidance. An oesophagogram done using a water soluble contrast (Gastroconray) showed a minor leak from the oesophagus. These patients were managed conservatively (nil orally, pharyngeal suction, intravenous fluids, and parenteral antibiotics) and all of them responded well to conservative treatment. Dilatation was resumed after a gap of three to four weeks and the strictures were successfully dilated to $15 \mathrm{~mm}$ in all without further complication. One patient in the corrosive group had a minor upper gastrointestinal haemorrhage which stopped spontaneously. This patient did not require blood transfusion or any other active treatment.

\section{Discussion}

This study clearly shows that dilatation is successful for most patients with corrosive oesophageal strictures in providing short and long term relief of dysphagia. The recurrence rate of dysphagia, although initially high, decreases over time. Furthermore, dilatation is safe and the incidence of complications with repeated treatments is quite low.

Although corrosive strictures were very often multiple, long, and tight, initial adequate dilatation with complete relief of symptoms was achieved in most patients (93.6\%). This figure is comparable with the success rate in our peptic stricture patients as well as in several other reports. ${ }^{2-7}$ It should, however, be mentioned that 
the number of sessions needed to achieve adequate dilatation was significantly higher in the corrosive group. Undoubtedly, these strictures are technically more difficult to dilate and adequate dilatation takes longer, but with persistence the ultimate results are good and comparable with those in patients with peptic strictures. On long term follow up, the mean number of symptomatic recurrences was greater in the corrosive group, but this was largely due to a very high recurrence rate during the early period of follow up. The recurrence rate fell significantly after 12 months in the corrosive group and after 36 months, the recurrence rate was similar to that in the peptic stricture patients.

The incidence of perforation in the present study is comparable with some of the earlier reports. ${ }^{57}$ Glick ${ }^{4}$ reported a very low complication rate of $0 \cdot 18 \%$ using Eder-Puestow metal olives followed by bougienage with Maloney dilators. The higher incidence of perforation in the present study is due to a larger number of patients with corrosive strictures which are technically more difficult to dilate. All perforations occurred in patients with long, eccentric, and tight strictures in whom, after the first few sittings, dilatation was performed without fluoroscopic control. It is recommended that fluoroscopy be used for dilatation of these high risk patients to ensure proper positioning of the guidewire. Early detection is very important too, and if the leak is minor, immediate conservative treatment may mean that surgical intervention can be avoided.

No comparative study of endoscopic dilatation with surgery in the management of corrosive oesophageal strictures has been reported. Indications for surgery are not clearly defined and there is no agreement on the ideal surgical procedure. ${ }^{121417}$ Reconstructive surgery using stomach, colon, or jejunum, with or without oesophagectomy, has been performed to relieve dysphagia. The early success of endoscopic dilatation is comparable with surgery. However, surgery is associated with a significant risk of early (anastomotic leak, bowel necrosis, pneumothorax etc) and late (anastomotic strictures requiring dilatation, colonic herniation into pleura, etc) complications. Moreover, the immediate mortality in surgical series ranges from $5 \cdot 7$ to $20 \%$, while no death has been noted with endoscopic dilatation. In view of nil mortality, low morbidity, and the high success rate, we feel that dilatation should be the first line of treatment for these patients.

In summary, our study shows that endoscopic dilatation is an effective and safe treatment for short and long term relief of dysphagia in patients with corrosive oesophageal strictures. Although these strictures are more difficult to dilate than other benign strictures, in experienced hands most patients can be treated successfully. The recurrence rate is high initially but it falls over time and is similar to that in the peptic stricture group after three years of follow up. In view of high efficacy and safety, it is recommended that patients with corrosive strictures should be considered first for endoscopic dilatation. Surgery should be undertaken only in those who do not respond to dilatation treatment.

1 Williamson RCN. The management of peptic oesophageal strictures. Br 7 Surg 1975; 62: 448-54

2 Lanza FL, Graham DY. Bougienage is effective therapy for most benign oesophageal strictures. $\mathscr{F} A M A$ 1978; 3: 121-8.

3 Ogilvie AL, Ferguson R, Atkinson M. Outlook with conservative treatment of peptic esphageal structures. Gut 1980; 21 : tive treat.

4 Glick ME. Clinical course of oesophageal strictures managed by bougienage. Dig Dis Sci 1982; 27: 884-8.

5 Wesdorp ICE, Bartelsman JFWM, den Hartog Jager FCA, Huibregtse K, Tytgat GN. Results of conservative treatment of benign oesophageal strictures: a follow up study in 100 patients. Gastroenterology 1982; 82: 487-93.

6 Rago E, Boesby S, Spencer J. Results of Eder-Puestow dilatation in the management of oesophageal peptic strictures. Am f Gastroenterol 1983; 78: 6-8.

7 Patterson DJ, Graham DY, Smith JL, Schwartz JT, Alpert E, Lanza FL. Natural history of benign oesophageal strictures treated by dilatation. Gastroenterology 1983; 85: 346-50.

8 Cox JGG, Winter RK, Mastin SC, Jones R, Buckton GK, Hoare RC, Sutton DR, Bennett JR. Balloon or bougie for dilatation of benign oesophageal strictures? An interim dilatation of benign oesophageal strictures? An interim report of

9 Dilawari JB, Singh S, Rao PN, Anand BS. Corrosive acid ingestion in man - a clinical and endoscopic study. Gut 1984; 25: 183-7.

10 Zargar SA, Kochhar R, Nagi B, Mehta S, Mehta SK. Ingestion of corrosive acids. Spectrum of injury to upper gastrointestinal tract and natural history. Gastroenterology 1989; 97: 702-7.

11 Broor SL, Kumar A, Chari ST, Singal A, Misra SP, Kumar N, et al. Corrosive oesophageal strictures following acid ingestion: Clinical profile and results of endoscopic dilatation. tion: Clinical profile and results of end

12 Fatti L, Marchand P, Crawshaw GR. The treatment of caustic strictures of the oesophagus. Surg Gynaecol Obstet 1956; 102: strictures

13 Atkinson M, Ferguson R, Ogilvie AC. Management of malignant dysphagia by intubation at endoscopy. $\mathcal{F}$ Roy Soc Med 1979; 27: 894-7.

14 Petrov BA. Retrosternal artificial oesophagus from jejunum and colon. Surgery 1959; 45: 890-8.

15 Ti TK, Sivaloganathan V. Oesophageal resection with cervical oesophagogastrostomy for

16 Belsey R. Corrosive strictures. In: Stipa S, Belsey RHR Moraldi A, eds. Medical and surgical problems of the Moraldi A, eds. Medical and surgical problems of the oesophagus. Serono

17 Gerzic ZB, Knezevic JB, Milicevic MN, Jovanovic BK. Oesophagocoloplasty in the management of postcorrosive strictures of the oesophagus. Ann Surg 1990; 211: 329-36. 